\title{
Evaluation of Water Storage Change of Inland Cryosphere in Northwestern China
}

\author{
Min Xu, ${ }^{1}$ Shichang Kang, ${ }^{1,2}$ and Jiazhen $\mathrm{Li}^{1}$ \\ ${ }^{1}$ State Key Laboratory of Cryospheric Science, Cold and Arid Regions Environmental and Engineering Research Institute, \\ Chinese Academy of Sciences, Lanzhou 730000, China \\ ${ }^{2}$ CAS Center for Excellence in Tibetan Plateau Earth Sciences, Chinese Academy of Sciences, Beijing 100101, China
}

Correspondence should be addressed to Min Xu; careerigis@163.com

Received 25 December 2014; Revised 14 March 2015; Accepted 14 March 2015

Academic Editor: Hiroyuki Hashiguchi

Copyright (C) 2015 Min Xu et al. This is an open access article distributed under the Creative Commons Attribution License, which permits unrestricted use, distribution, and reproduction in any medium, provided the original work is properly cited.

\begin{abstract}
The Gravity Recovery and Climate Experiment (GRACE) satellite mission provides measurements of Earth's static and timevariable gravity fields with monthly resolution. In this study, changes of water storage in northwestern China were determined by GRACE monthly gravity field data obtained from 2003 to 2010. Comparisons of water storage change (WSC) simulated by a four-dimensional assimilation model (Noah) and observed by GRACE revealed similar patterns of change and a correlation coefficient of $0.71(P<0.05)$. Trend analysis indicated significant changes in the spatiotemporal variation of WSC in northwestern China during the 8-year study period, which were stronger in the east than in the west and more pronounced in the south than in the north. The most pronounced increase in water storage occurred in Gansu and Qinghai provinces, but, overall, water storage increased by $0.61 \mathrm{~mm} / \mathrm{a}$ over northwestern China during the study period. Clear seasonal variations of WSC and precipitation were found, because glacial meltwater and precipitation are the main sources of water in the hydrosphere; meanwhile, the distributions of glaciers and permafrost also affect the spatial distribution of WSC.
\end{abstract}

\section{Introduction}

The cryosphere is an important component of the global water cycle, and its sensitivity to climate change has been a subject of much concern. In particular, since the 1980s, the global cryosphere has undergone significant changes due to global warming, which have important consequences with regard to the global water cycle [1]. It has been in the principal cryospheric region of northwestern China, including Xinjiang (XJ), Gansu (GS), Ningxia (NX), and Qinghai $(\mathrm{QH})$ provinces and Tibet, where these changes in the water cycle have been most pronounced [1]. Therefore, the study of the spatiotemporal variation of water storage change (WSC) in these areas has importance regarding the understanding of the water cycle, climate change, agricultural production, and natural disasters.

In northwestern China water sources are mainly melting snow and ice and groundwater recharge. For example, mountain runoff is the only source that recharges surface and subsurface runoff in the basin of the Xinjiang Plain
[2]. The socioeconomic development of northwestern China has led to increased water demand, overexploitation of water resources, and consequent water shortages that have become a major restriction to the ongoing development of the region $[3,4]$. WSC is an important measure that reflects the changes of regional water resources, which have become one of the most important issues regarding socioeconomic development in China.

It is difficult to estimate WSC using traditional longterm water balance calculations and estimations of the water resources of a watershed/region, and, therefore, it is often considered as zero on the annual scale. However, ignoring WSC could have significant impact on the estimated elements of the water balance under climate change scenarios. In estimating the water balance in the source region of the Yellow River, Xu et al. [5] showed that average evaporation calculated by the Sib2 model is $978.2 \mathrm{~mm}$, but when considering WSC, the average evaporation is $507.4 \mathrm{~mm}$. These results suggest that an assessment of WSC is crucial for understanding the changes of the water balance in northwestern China. 
WSC can be derived by calculating the difference between precipitation, evapotranspiration, surface runoff, and soil exchange of moisture and groundwater in the water cycle [6]. However, it is difficult to obtain an accurate estimation of the WSC of a region/watershed because of the lack of observational data and the high cost of the measurement methods. Some researchers have used satellite-derived gravity data to monitor long-term WSC and they have made considerable advances [7-9]. The advantage of satellite-based methods is their ability to reflect uniform region/basin-scale observations of water storage variations. Traditional remote sensing satellites can be used to detect the soil moisture of the land surface to depths of only tens of centimeters, and the spatial distribution of field stations for verification purposes is poor. However, to a certain extent, the Gravity Recovery and Climate Experiment (GRACE) satellite can compensate for such disadvantages, and it offers a new opportunity for the quantitative study of regional land WSC.

The variation in the gravity field detected by GRACE is mainly due to land WSC, ice masses (e.g., polar ice sheets, alpine glaciers ice cap), and other geophysical signals (e.g., postglacial rebound and deformation caused by earthquakes). Interference signals in the GRACE data are caused by the atmosphere and ocean mass variations, which can be removed using numerical simulation [10], and, therefore, following the removal of the geophysical signals, the WSC can be determined. Results show that the GRACE satellite can monitor the water equivalent change of the ground to about $0.9 \mathrm{~cm}$ and the precision can reach $1-1.5 \mathrm{~cm}[11,12]$. Some researchers have compared the results retrieved by GRACE with those calculated using global land surface process models. The two methods produce results that are similar in most areas, but there are also discrepancies related to difficulties in obtaining precise input data in some areas. GRACE data can overcome such problems and, thus, can provide a reference for the improvement of the accuracy of global land surface process models [13-16]. Strassberg et al. [17] used GRACE data to estimate the WSC over about $450,000 \mathrm{~km}^{2}$ of the American High Plains region and found good correlation ( $R=0.95$ ) between the WSC retrieved by GRACE and the measured soil moisture and groundwater data. In addition, WSC retrieved by GRACE has been used in cryosphericrelated research on permafrost activities and WSC in the Arctic. The results showed that WSC increased at a rate of $1.15 \mathrm{~km}^{3} / \mathrm{a}$ on the coast of Alaska, whereas it showed a rate of decline of $7.44 \mathrm{~km}^{3} / \mathrm{a}$ in the Yukon basin. Changes of the permafrost active layer might be an important reason behind the variation of WSC, and the results of the study suggest that GRACE satellite data could be used to analyze the variation of WSC in permafrost regions [18]. Chinese research on this subject has concentrated mainly on large areas, such as the Chinese continental region, Xinjiang and the surrounding mountainous area, and northern, northeastern, and southern regions of China $[4,15,16,19]$. Generally, these researches have involved regional quantitative descriptions of WSC, and they have established that different regions exhibit different variational features. Some studies have used GRACE satellite data to analyze the magnitude of WSC in the Three Gorges

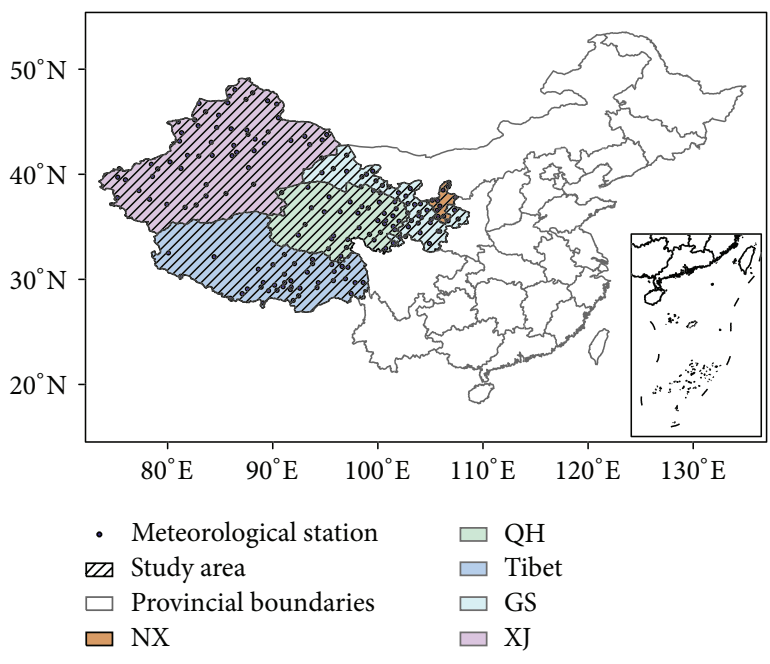

Figure 1: Study area.

Reservoir area and the Yangtze River and Heihe River basins. The amplitude of annual variation of WSC in the Yangtze River basin was up to $3.4 \mathrm{~cm}$ equivalent water height with the maximum value appearing in spring and early autumn. The root-mean-square error (RMSE) of the variation of WSC of the Three Gorges Reservoir was $1.3 \mathrm{~cm}$, for the amplitude of the annual variation of $0.1 \mathrm{~cm}$. In addition, the WSC of the Heihe River basin increased yearly from 2002 to 2008 [20-24]. These studies reveal that applications of GRACE data are lacking in depth and breadth, although they do indicate that GRACE satellite data could enhance the understanding of WSC, and provide a basis for better predictions of drought and changes in global water resources due to climate change. However, a comprehensive study of the WSC of the cryosphere and of its causes in northwestern China has not been reported previously. In this study, gravity information derived from GRACE satellite observations was used to retrieve monthly WSC, which was compared with results simulated by the Noah model to analyze WSC in northwestern China from 2003 to 2010. This work expands the spatiotemporal scale of the analysis of WSC in northwestern China, by considering the water resources of five provinces (Xinjiang, Gansu, Ningxia, Tibet, and Qinghai) and the Qinghai-Tibet Plateau and by discussing the effects on WSC of glaciers and the underlying permafrost.

\section{Study Area}

The study area incorporates Tibet and Gansu (GS), Qinghai $(\mathrm{QH})$, Ningxia (NX), and Xinjiang (XJ) provinces with an area of about $2,808,000 \mathrm{~km}^{2}$ (Figure 1). The climate is mainly influenced by monsoon and westerlies, and precipitation declines from the east to the west and from the south to the north. Annual precipitation is about $400 \mathrm{~mm}$ in the east, which decreases to $200 \mathrm{~mm}$ in the west or $50 \mathrm{~mm}$ below. The main topographic features of the area are plateaus, basins, and mountains, including the Loess and Qinghai-Tibet Plateaus, the Tarim, Zhungeer, and Qaidam basins, and the Tianshang, 
Qianlian, Karakorum, and Kunlun Mountains. The QinghaiTibet Plateau, sometimes referred to as the world's "third pole," is the largest glacial resource in China. The total ice volume is $2798 \mathrm{~km}^{3}$, which accounts for $50 \%$ of the ice reserves. The ice covers about $32320 \mathrm{~km}^{2}$, which accounts for $54.4 \%$ of the entire area. There are 22468 glaciers within this region, and the permafrost area extends over about $1.3 \times$ $10^{6} \mathrm{~km}^{2}[25,26]$. There are 18311 glaciers in XJ, accounting for $46.8 \%$ of the total number of glaciers in China, covering an area of $24721.93 \mathrm{~km}^{2}$. The total of ice reserves are $2623.4 \mathrm{~km}^{3}$, and the water storage of the glaciers is $23611.2 \times 10^{8} \mathrm{~m}^{3}$ [27].

\section{Materials and Methods}

3.1. Precipitation Data and Spatial Interpolation Method. Precipitation data from 2003 to 2010 were obtained from national meteorological stations within the study area and corrected for the influence of wind [28]. Furthermore, to improve the surface accuracy of precipitation within the study area, the data were interpolated using Kriging with consideration of elevation [29]. This method uses precipitation and site elevation data to perform a linear regression. The spatial $P_{r}$ was calculated using the formula for linear regression; the residuals (regressed precipitation minus measured precipitation) were interpolated using the Kriging spatial interpolation method, and then the spatial $P_{r}$ was added to the spatial residuals, which provides the spatial distribution of precipitation:

$$
P_{\text {result }}=P_{r}+P_{\text {residual }},
$$

where $P_{\text {result }}$ is the spatial precipitation, $P_{r}$ is the rasterized precipitation regressed by elevation, and $P_{\text {residual }}$ is the spatial residual (units of precipitation: $\mathrm{mm}$ ).

3.2. Change of Precipitation. Precipitation is the main source of land surface water and changes in precipitation affect evaporation, runoff, and WSC. In this study, the change of precipitation was calculated using the following formula:

$$
P_{c}=P_{i}-P_{i-1} \text {, }
$$

where $P_{c}$ is the change of precipitation, $P_{i}$ is the precipitation in month $i, P_{i-1}$ is the precipitation in the preceding month, and $i$ is the month (from 1 to 12 ).

3.3. Retrieval Method for WSC Data. This study used Release04 (R4) Level-3 grids provided by the GRACE Science Team centers. The global grids comprise 1 -arc-degree water equivalent mass change complete to degree and order $60[8,12]$. The GRACE R4 Level-3 (300 km Gauss-smoothing kernel) land and ocean monthly grids from 2003 to 2008 were combined to provide global coverage [20,23]. Glacial isostatic adjustment or solid mass flow within Earth's mantle, following the decay of the Pleistocene Laurentide and Cordilleran ice sheets in North America and Scandinavia, was applied to the GRACE grids [30].
3.4. Soil Moisture Simulated by Model. WSC represents a vertically integrated measure of variation of water storage that includes soil moisture, groundwater, surface water, snow and ice, and biomass. A previous study of WSC in the High Plains of the United States showed that soil moisture and groundwater are the primary contributors to terrestrial water storage variability and that the variations due to snow and ice, biomass, and surface water are relatively minor [31]. Hydrological models can be divided into two categories based on global and continental scales: land surface models (LSMs) and water budget models. A land surface process model describes the composition of WSC, which includes groundwater, surface water, water exchange, and storage.

In this study, in order to compare the results retrieved by GRACE, the Noah LSM was used to simulate soil moisture. The Noah model was developed by the Research Applications Laboratory of the National Center for Atmospheric Research (NCAR), and a four-dimensional assimilation system was used to calculate the simulated results. The unsaturated zone of the soil was divided into four layers, the thicknesses of which from the soil surface to the bottom were $0.1,0.3$, 0.6 , and $1.0 \mathrm{~m}$. Model input data included precipitation, solar radiation, surface air pressure, humidity, and surface wind speed. The shortwave and longwave radiation data were provided by the Air Force Weather Agency agrometeorological simulation system (AGMET), and all other data were obtained from national meteorological stations. Model output included four layers of soil moisture change with temporal resolution of 1 month and spatial resolution of $1^{\circ} \times 1^{\circ}$. It is important to note that model simulations are ineffective in permafrost zones.

3.5. WSC Cycle. To study the extent and period of WSC within study area quantitatively, the least-squares method was used to calculate the cycle and amplitude of regional WSC:

$$
y(t)=A \cdot \sin \left[\frac{2 \pi \cdot(t-\phi)}{\omega}\right],
$$

where $A$ is amplitude, $\phi$ is phase, and $\omega$ is the cycle. Amplitude represents the intensity of WSC and the cycle represents the length of WSC in the time series.

\section{Results and Discussion}

4.1. Results of WSC Retrieved by GRACE and Simulated by Noah. The results of WSC retrieved by GRACE and simulated by Noah for representative periods of summer (August 2007) and winter (December 2008) are shown in Figure 2. It can be seen that over a large area the two results have similarities. For example, the WSC exhibits a state of loss in the west of XJ and NX, whereas it shows a state of gain in the middle of GS and the Qilian Mountains. However, in some small parts, they exhibit differences. Overall, the WSC retrieved by GRACE demonstrates better continuity than that simulated by Noah.

A comparison of the two results as time series (Figure 3) reveals that both exhibit seasonal change and demonstrate 

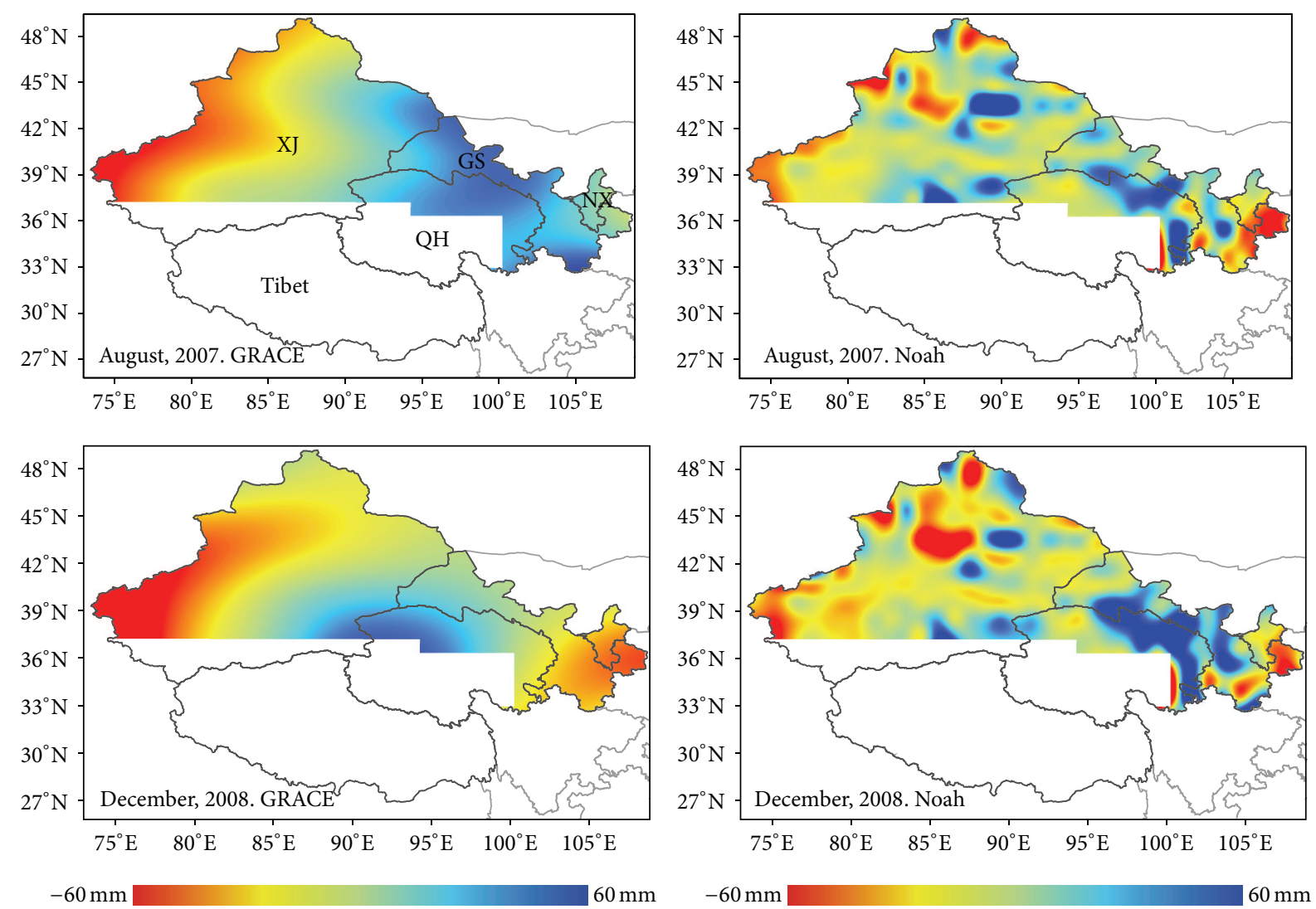

FIGURE 2: Results of WSC retrieved by GRACE and simulated by Noah.

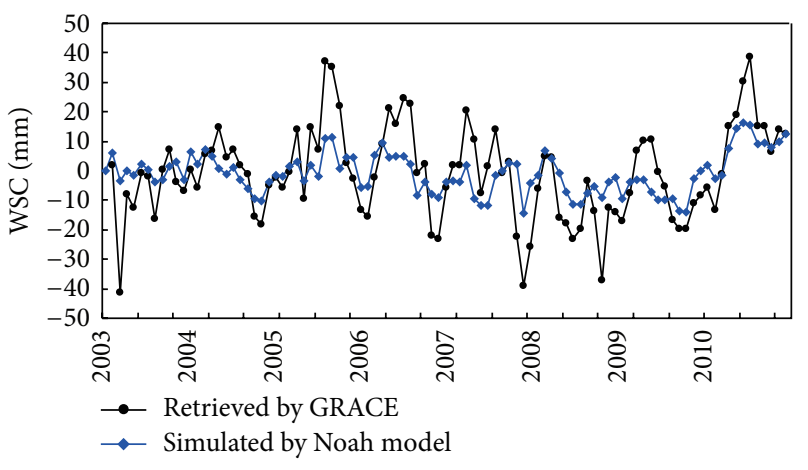

(a)

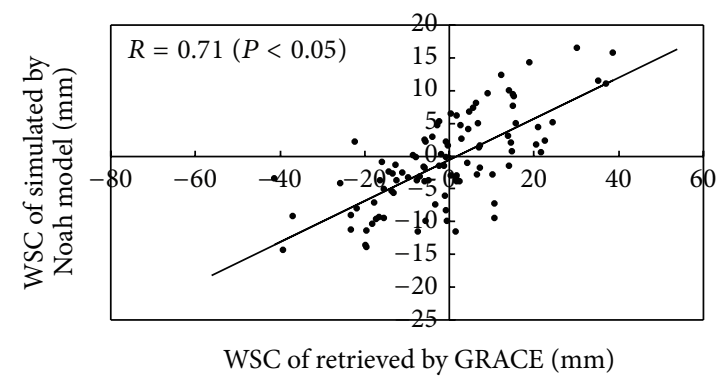

(b)

FIGURE 3: Correlation of WSC retrieved by GRACE and simulated by Noah as time series.

a fluctuating feature (correlation between them is 0.71). However, as can be seen, the range of the values retrieved by GRACE is much larger than that simulated by Noah. One reason for this is that GRACE data can reflect deeper soil water equivalent.

It should be pointed out that although the two results coincide, they have differences in scale, and there are two reasons for this. The first is that the expressions of the two results are different; Noah only reflects changes of soil humidity, whereas GRACE reflects soil, surface water, glaciers, and frozen soil moisture. The other reason is that the distribution of the stations is sparse, which limits the results simulated by the model.

4.2. Temporal and Spatial Patterns of WSC and Precipitation over Northwestern China. WSC was retrieved from GRACE satellite data from 2003 to 2010 over northwestern China, and the distributions of the average WSC and of the average change of precipitation, calculated using formulas (1) and (2), are shown in Figures 4(a) and 4(b), respectively. As can be seen, there is much less change in the south than in the north and much more change in the east than in the west. 


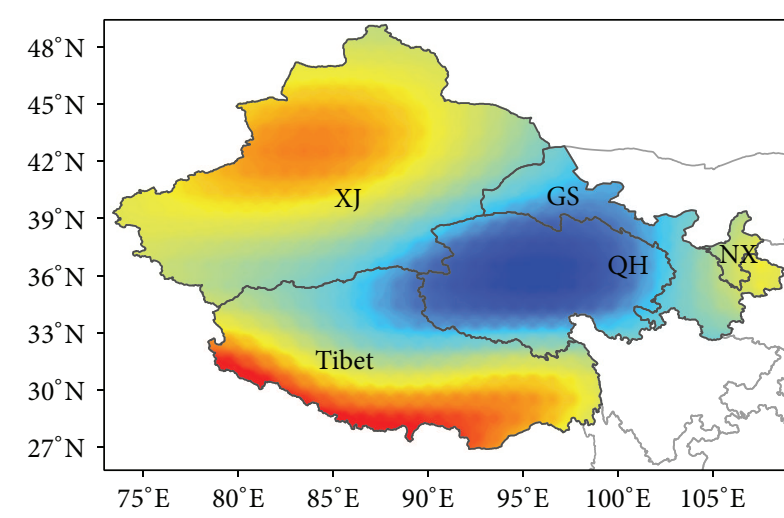

Change of $\operatorname{WSC}(\delta)(\mathrm{mm})$

High: 248.3

Low: -291.1

(a)

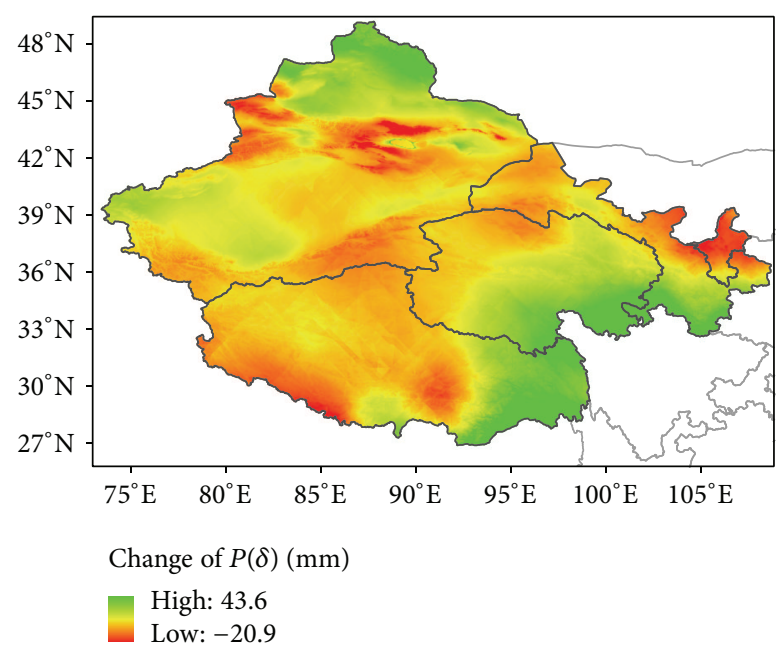

(b)

FIGURE 4: Temporal and spatial patterns of average annual WSC and precipitation over northwestern China from 2003 to 2010.

WSC is in a surplus state in QH and GS, but precipitation does not coincide with the distribution of WSC in this area, which means that the spatial distribution of precipitation is not the only factor driving the spatial distribution of WSC. Precipitation is the main source of WSC, but degradation of the permafrost and increased thickening of the active layer of seasonally frozen soil also increase the storage capacity of the area [5]. WSC is in a state of loss in most parts of $\mathrm{XJ}$, especially in western regions where the largest loss value reaches $-175 \mathrm{~mm}$. The WSC shows an intense state of loss in the Himalayas where the value is about $-291.1 \mathrm{~mm}$. This is consistent with research that claims there has been glacial mass balance loss in this area and where the retreat has been faster in the middle and west of the region [32, 33]. However, WSC shows gains in the Karakorum region and the Altai Mountains, which could corroborate research that has shown that glaciers in these areas have exhibited mass stability or even expansion. As can be seen, the precipitation has increased in these areas and previous studies have shown that snowfall is less sensitive to warming [34]. The WSC shows serious losses in XJ, except in the north. There are 18311 glaciers in XJ with a total area of $24721.93 \mathrm{~km}^{2}$, but most of the glaciers in XJ are retreating $[35,36]$, which means that the water resource has decreased. Across the entire study area, WSC is between -291.1 and $248.3 \mathrm{~mm}$. As shown in Figure 4(b), the range of variation of precipitation is -20.9 to $43.6 \mathrm{~mm}$ with the distribution showing the characteristic of a decrease from southeast to northwest. Precipitation shows a reduction in most of the region, although it shows an increase in northern XJ, eastern Tibet, and QH. The distributions of WSC and precipitation have spatial differences, but they do show localized consistency (such as southeastern QH).

It can be seen from Figure 5 that the amplitude of variation of WSC across the study area is -36.4 to $55.9 \mathrm{~mm}$. This means that the maximum value of increased water is about $55.9 \mathrm{~mm}$ equivalent water height, and the minimum value is $-36.4 \mathrm{~mm}$ equivalent water height. Monthly

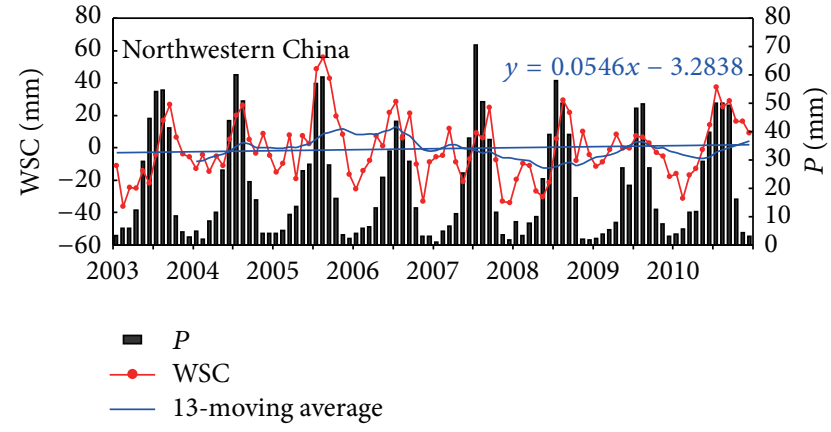

FIGURE 5: Time series of WSC and precipitation $(P)$ over northwestern China from 2003 to 2010.

precipitation is about 1.1-70.5 mm. Generally, WSC shows a slight upward trend, but the difference between inflow and outflow is increasingly small. WSC and precipitation have obvious seasonal variation and consistent change processes. The study area is located in inland areas of the mid-latitude westerly belt, where sources of water vapor depend mainly on the zonal westerly circulation and the Indian Ocean monsoon [37, 38]. Rainfall is concentrated mainly from May to September, which is when the WSC generally increases and the peak value appears in this period. Precipitation is relatively small from December to March, but evaporation is large, and, therefore, the WSC is at a loss. The characteristics of variation of precipitation have a dominant effect on WSC in the time series. In northwestern China, the WSC increases slightly year by year from 2003 to 2010; the average rate of increase is about $0.61 \mathrm{~mm} / \mathrm{a}$, and the total increase in the quantity of water is about $1.47 \times 10^{10} \mathrm{~m}^{3}$.

4.3. Monthly Average WSC from 2003 to 2010. The distributions of monthly average WSC indicate differences during the years for which it was retrieved by GRACE (Figure 6). It can 

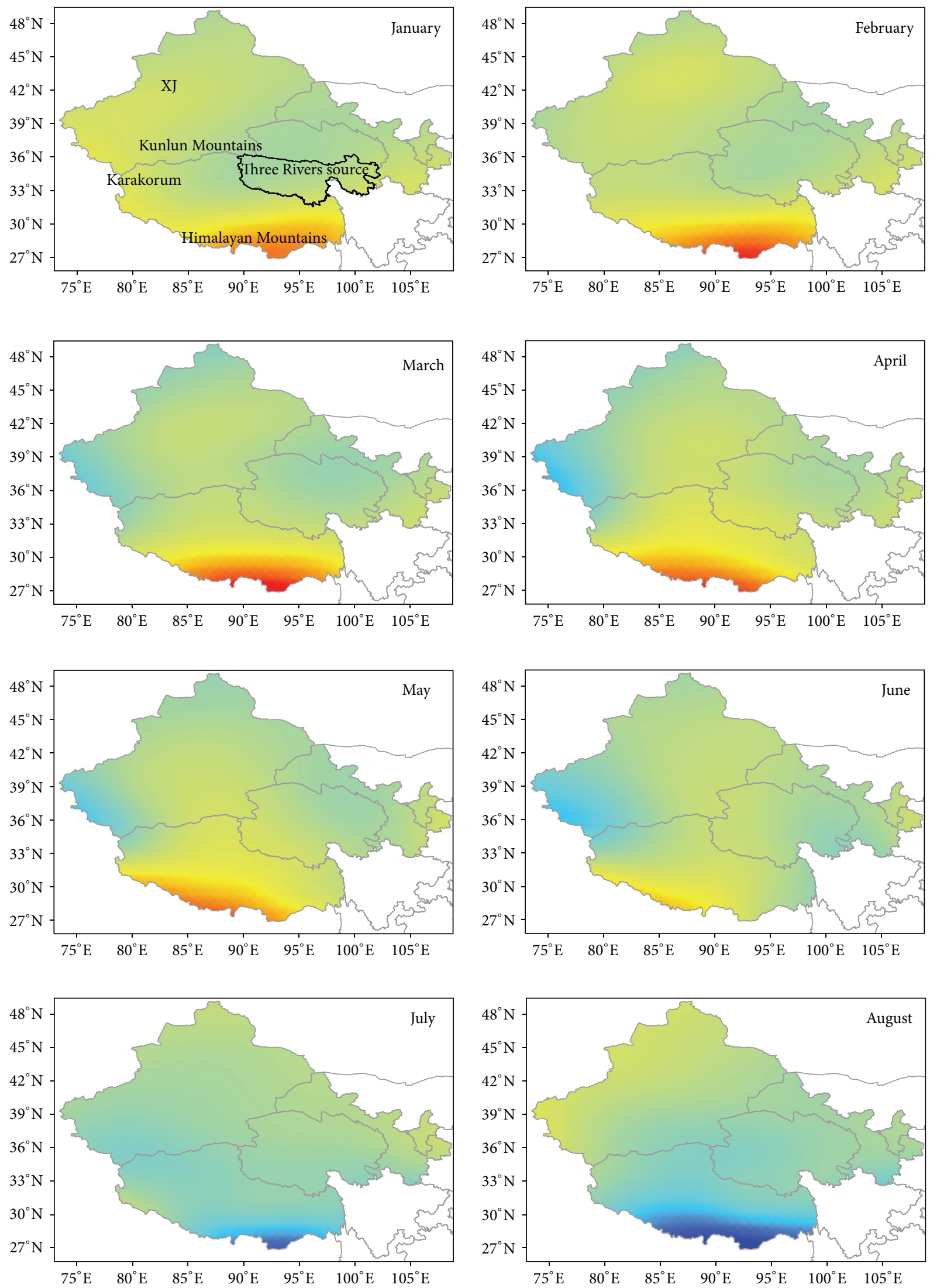

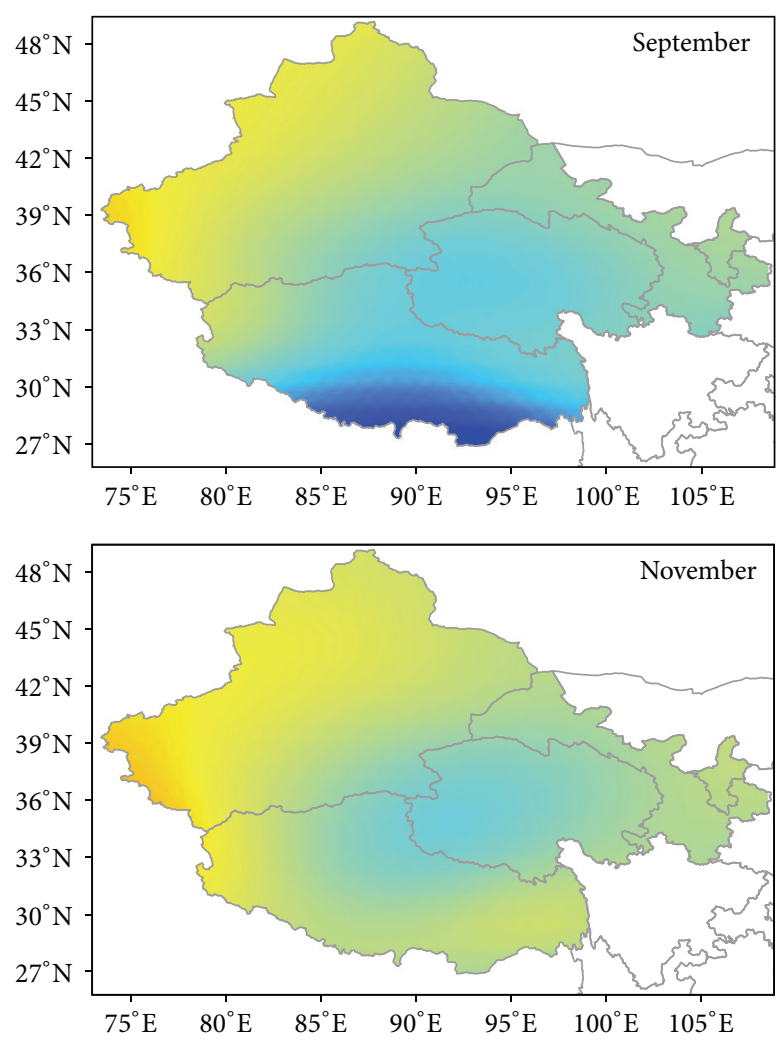

$150 \mathrm{~mm}$

$-150 \mathrm{~mm}$
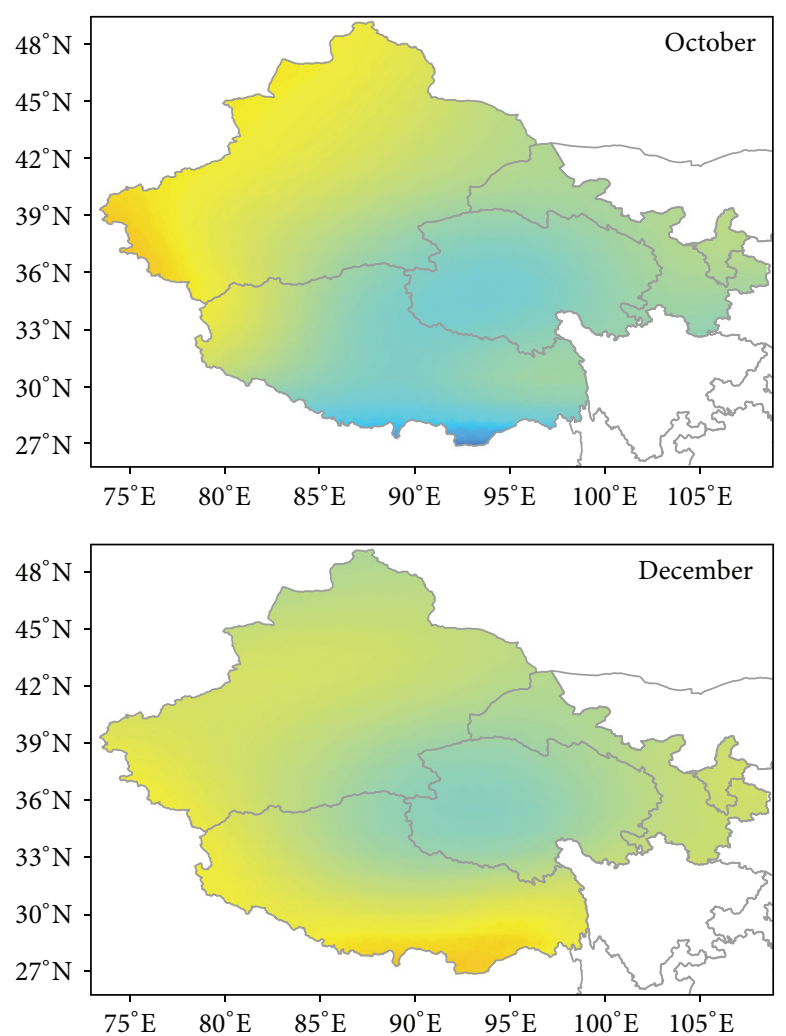

$150 \mathrm{~mm}$

Figure 6: Monthly averages of WSC from 2003 to 2010.

be seen that the WSC is in a state of loss in the Himalayan region from January to June and in December, with particularly serious losses in February and March. However, it is in a state of gain from July to November, although as the months proceed, the state of gain weakens. That pattern is due to the low precipitation and high evaporation during spring and winter and greater precipitation brought in summer by the Indian monsoon, which brings much more water vapor $[39,40]$. The XJ region is influenced by the westerly circulation, which brings increased levels of water vapor and a state of gain in western parts from March to July. This state is particularly evident in the Karakorum and Kunlun Mountains; the state of gain moves west to middle. The WSC is in a state of gain from January to March in the Three Rivers source area, because spring snowmelt runoff begins, which results in a of state of loss from April to June. This area is influenced by the rainy season as well as by glacial meltwater supply during July, which means that the WSC is in a state of gain from July to February of the following year.

4.4. Annual Distribution of WSC from 2003 to 2010. We also calculated the annual distribution of WSC (Figure 7). It can be seen from the figure that the WSC is in a state of gain from March to July in XJ but that it is in a state of loss for the rest of the year. The maximum value (about $13.5 \mathrm{~mm}$ ) appears in July and the minimum value (about $-28.2 \mathrm{~mm}$ ) is in October. The WSC of GS shows a state of loss in January,
February, and December, whereas it is in a state of gain for the other months and the maximum value (about $21.6 \mathrm{~mm}$ ) occurs in September. The WSC is in a state of loss in QH from April to June, principally because the area includes the Three Rivers source area and the runoff of spring snowmelt leads to supplementary losses. In the other months, WSC is in a state of gain and the maximum value (about $44.4 \mathrm{~mm}$ ) occurs in September. The WSC is irregular in NX, showing a state of gain in March and April and from August to December, but is in a state of loss in the other months; the maximum and minimum values occur in September and December, respectively. The WSC is more consistent in Tibet and on the Qinghai-Tibet Plateau. It is in a state of gain from July to November but in a state of loss in the other months. The maximum value appears in September and the minimum in April.

4.5. Process of WSC in Northwestern China. We calculated the WSC and precipitation during 2003-2010 in XJ, GS, QH, NX, and Tibet and on the Qinghai-Tibet Plateau (Figure 8). It can be seen that regional WSC exhibits strong seasonal fluctuations, but changes in precipitation are not obvious. The WSC increases in GS and QH and on the QinghaiTibet Plateau from 2003 to 2010, at rates of 3.63, 9.68, and $2.49 \mathrm{~mm} / \mathrm{a}$, respectively. The WSC decreases in XJ, NX, and Tibet at rates of $-1.49,-2.54$, and $-3.05 \mathrm{~mm} / \mathrm{a}$, respectively. 

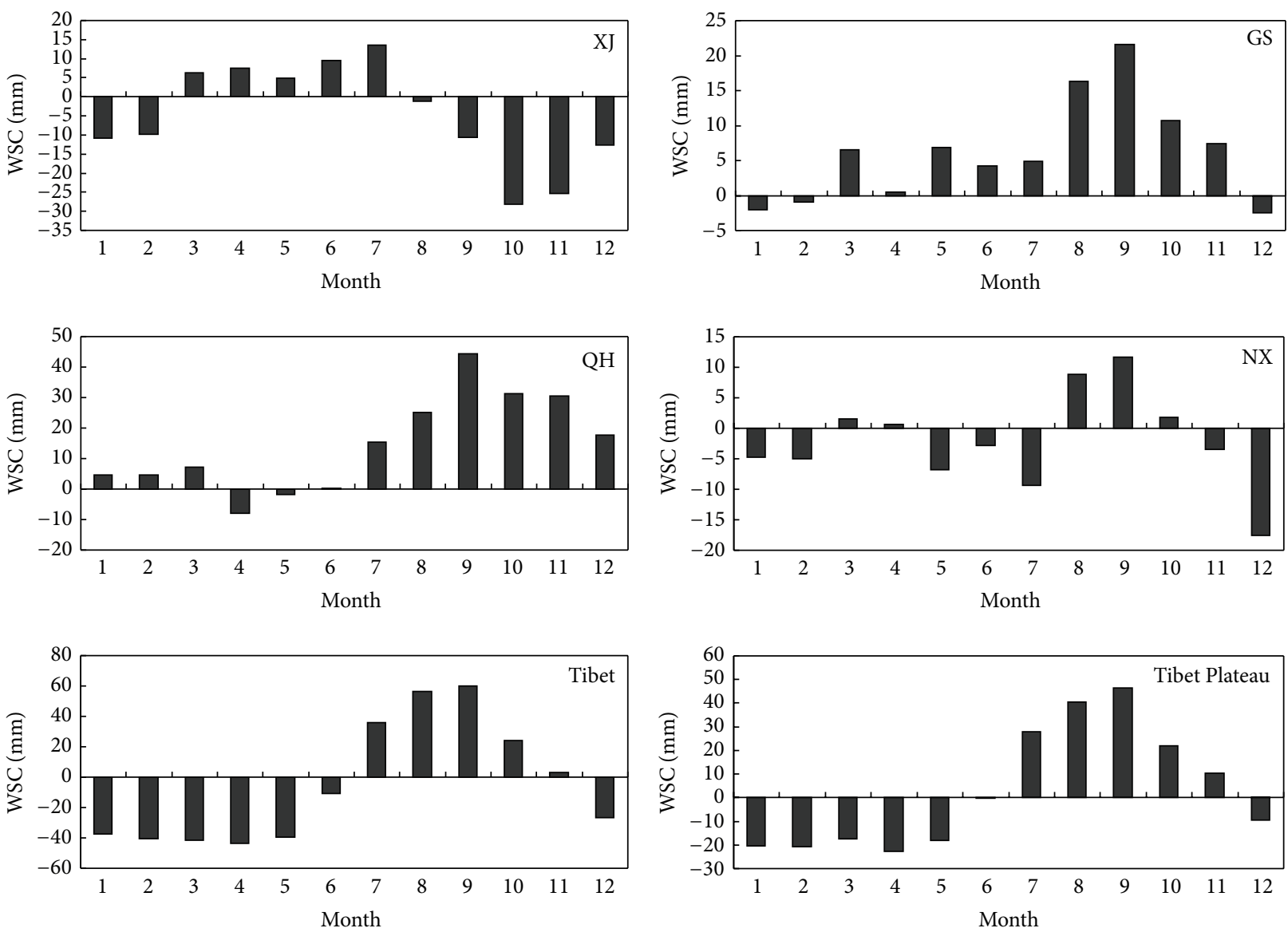

FIgURE 7: Annual distributions of WSC from 2003 to 2010.

TABle 1: Amount of WSC over northwestern China from 2003 to 2010.

\begin{tabular}{lcc}
\hline Region & $\begin{array}{c}\text { Rate of change } \\
(\mathrm{mm} / \mathrm{a})\end{array}$ & $\begin{array}{c}2003-2010 \mathrm{WSC} \\
\left(10^{9} \mathrm{~m}^{3}\right)\end{array}$ \\
\hline $\mathrm{XJ}$ & -1.49 & -195 \\
$\mathrm{GS}$ & 3.63 & 117 \\
$\mathrm{NX}$ & -2.54 & -10.3 \\
$\mathrm{QH}$ & 9.68 & 555 \\
Tibet & -3.05 & -294 \\
Qinghai-Tibet Plateau & 2.49 & 506 \\
\hline
\end{tabular}

The total amount of water increased by about $555 \times 10^{9} \mathrm{~m}^{3}$ in QH and it decreased by about $294 \times 10^{9} \mathrm{~m}^{3}$ in Tibet (Table 1).

The trends of WSC retrieved by GRACE are in line with the normal patterns and we analyzed the cycles using (3). The amplitude of the land surface water resource reflects the intensity of the hydrological cycle, and the cycle represents the duration of the cycle of WSC. As can be seen from Table 2, the smallest intensity of WSC is $3.4 \mathrm{~mm}$ in QH, which means that the WSC is in a steady state in this area. The largest amplitude is $11.5 \mathrm{~mm}$ in GS, indicating that the change of water resource in this area has greater complexity and uncertainty and that although the WSC of the area has
TABLE 2: Cycle of WSC over northwestern China.

\begin{tabular}{lcc}
\hline Region & Amplitude $(\mathrm{mm})$ & Cycle (month) \\
\hline XJ & 4.1 & 18 \\
GS & 11.5 & 21 \\
QH & 3.4 & 20 \\
NX & 7.8 & 25 \\
Tibet & 7.9 & 20 \\
Qinghai-Tibet Plateau & 3.2 & 22 \\
\hline
\end{tabular}

increased overall, the distribution of WSC is unequal. The largest cycle of WSC is in NX, which is about 25 months, and the smallest is in XJ, which is about 18 months. This reflects the greater development of agriculture and industry in XJ, which accelerates the speed of the water cycle. Whether on temporal or spatial scales, the distribution of WSC in northwestern China is shown to be heterogeneous.

4.6. Influence of Glaciers and Permafrost on WSC. The distributions of glaciers, permafrost, and talik (a layer of ground that remains unfrozen year-round) affect the characteristics of surface drainage and groundwater storage changes in northwestern China [5]. The dynamics of permafrost, talik, and the active layer exert significant influences on surface 

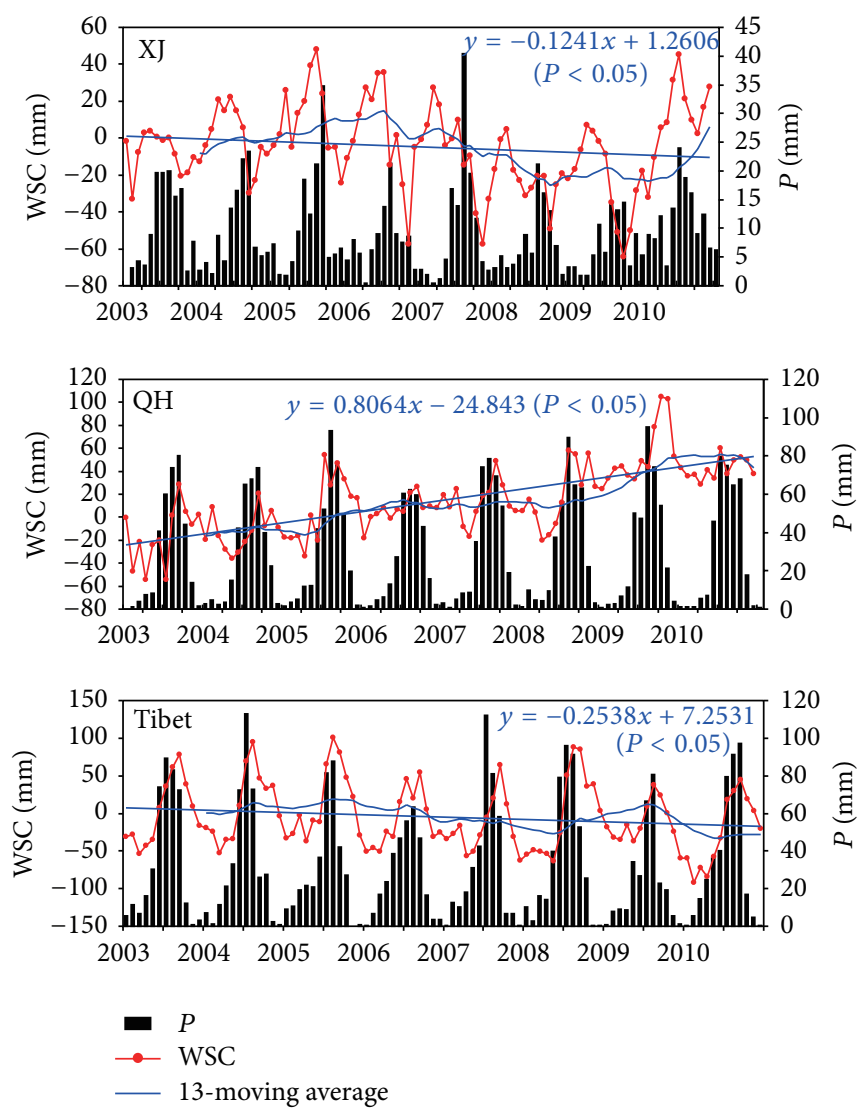
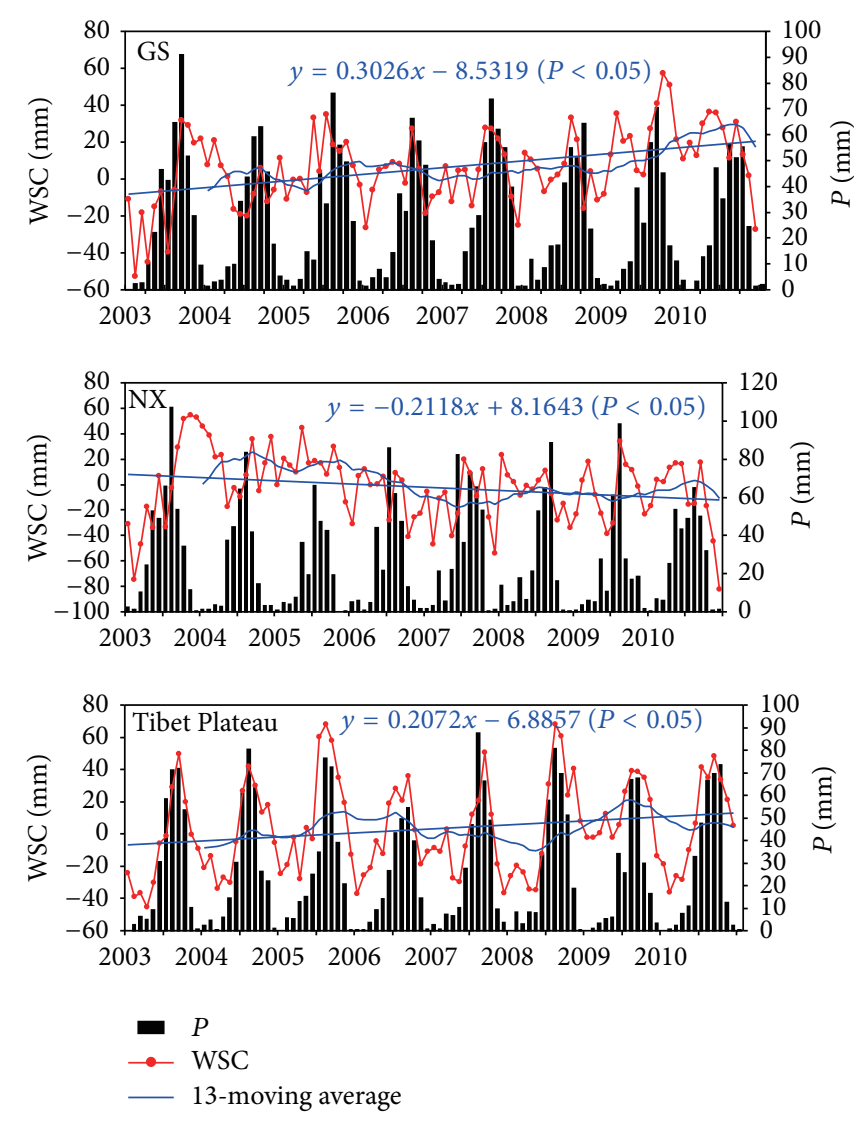

FIgURE 8: Time series of WSC and precipitation $(P)$ over each of the study areas from 2003 to 2010.

and groundwater hydrology and geomorphology in area $\mathrm{A}$ of Figure 9. Area A is a region of numerous and sometimes quite large thermokarst thaw ponds, lakes, and drained thawlake basins $[39,40]$. Area B has a large number of glaciers that have retreated considerably [36]. Glacial meltwater flows into area $\mathrm{B}$ from the northern slopes of the Himalayas. However, between areas A and B, a considerable amount of predominantly continuous permafrost prevents movement of the surface water into the groundwater. Thus, the active layer increases and thickens, which leads to greater infiltration of surface water into the groundwater, which results in increased water storage in area A. The GRACE monthly water equivalent changes capture the changes of the base flow from groundwater and surface water in the permafrost area of the Qinghai-Tibet Plateau. In related research, GRACE-derived WSC has been found to increase in the watershed of the Lena and Yenisei rivers [41]. These watersheds encompass large areas of both continuous and discontinuous permafrost zones and talik.

Glaciers have exhibited mass stability or even expansion in area D of Figure 9 [42-44]. The results retrieved by GRACE also reflect that the WSC has increased in this area. Research has indicated that the Karakorum seasonal cycle is dominated by nonmonsoonal winter precipitation, which has uniquely protected it from reductions in annual snowfall under climate warming during the early part of the 21st

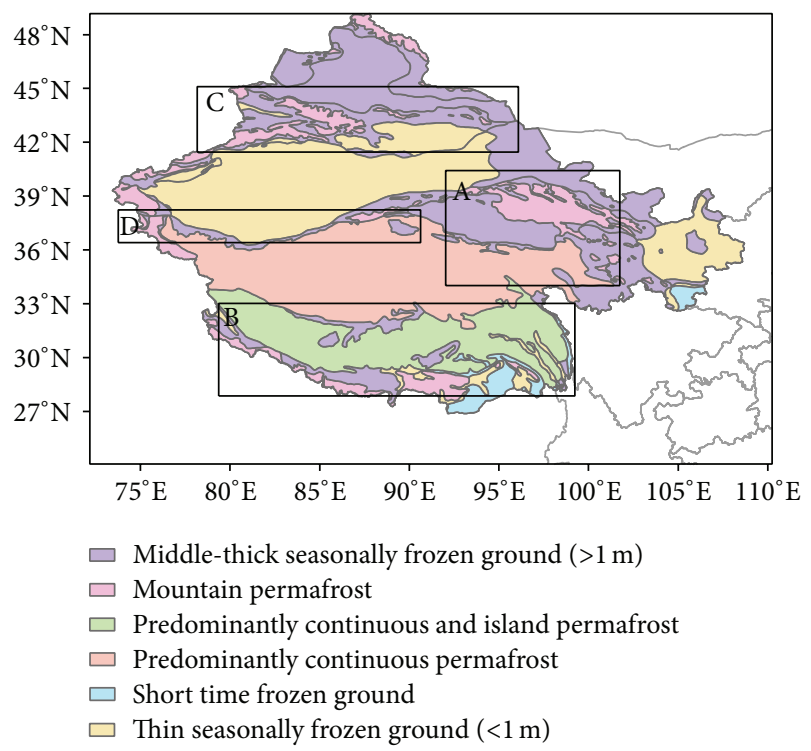

FIGURE 9: Distribution of frozen soil types over northwestern China.

century [34]. Glacial mass loss has occurred across areas C and A in Figure 9 [35]. Since the early 2000s, the trend of precipitation has not changed much $[45,46]$, whereas the 


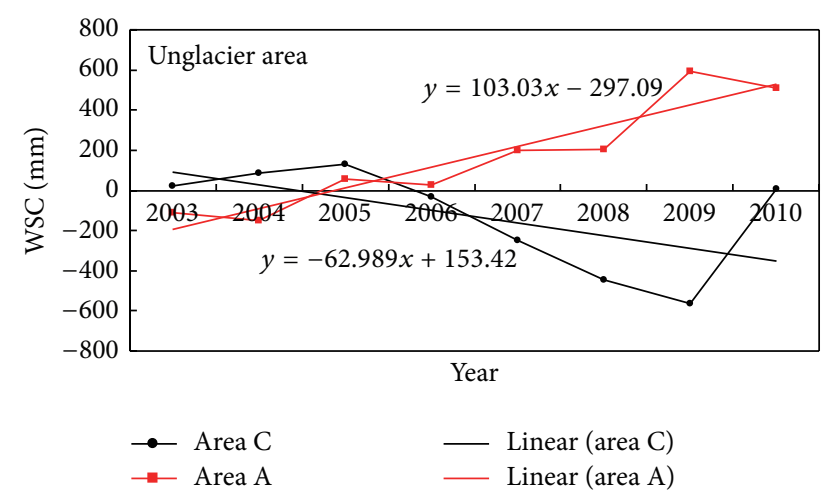

FIGURE 10: WSC of nonglaciated areas of A and C.

WSC exhibits large differences (Figure 4(a)). The WSC in the Tianshan Mountains part of area $\mathrm{C}$ has decreased, whereas it has increased in the Qilian Mountains part of area A. The total area of the Tianshan Mountains is $270,000 \mathrm{~km}^{2}$, and the area of glaciers is approximately $9225 \mathrm{~km}^{2}$, which accounts for $3.41 \%$ of the total area. The area of permafrost is about $63,000 \mathrm{~km}^{2}$, which accounts for $23 \%$ of the total area. The area of the Qilian Mountains is $198,000 \mathrm{~km}^{2}$ and the area of glaciers is approximately $1931 \mathrm{~km}^{2}$, which accounts for about $1 \%$ of the total area. The area of permafrost is about $100,000 \mathrm{~km}^{2}$, which accounts for $50 \%$ of the total area. Both regions rely mainly on the supplement of meltwater runoff from the mountains. However, the WSC is in a state of loss in area $\mathrm{C}$, which shows that the glacial meltwater flows out this area but that less surface water infiltrates into the groundwater. Furthermore, area A has a greater distribution of permafrost, and thus the thickened active layer as well as more ponds might store more water which caused an increase of WSC (Figure 10).

\section{Conclusions}

(1) The WSC in the northwestern China was retrieved using GRACE data and the results were compared with the simulations of the Noah model. The total amount of WSC in northwestern China was calculated and analyzed and discussed based on the regional WSC of five provinces and the QinghaiTibet Plateau. The retrieved results agree well with the simulations by Noah; the correlation coefficient is 0.71 $(P<0.05)$. And retrieved results reflect the seasonal change, interannual variation, and spatial distribution of the total water resource within the study area.

(2) The interannual variability of WSC was found to have decreased in XJ, NX, and Tibet but increased in GS and QH and on the Qinghai-Tibet Plateau. The study area encompasses the principal regions of glaciers and permafrost in China, which have an effect on the annual regional differences in WSC in XJ, GS, QH, NX, Tibet, and the Qinghai-Tibet Plateau. Seasonal changes of WSC were clear, but the seasonal differences and cycles and annual magnitudes of change reflect the imbalance of water resource distribution in northwestern China.

(3) Recent warming leads to the degradation of permafrost and retreat of glaciers. Permafrost plays an important role in the water cycle, and the increase and thickening of the active layer can lead to greater infiltration of surface water into the groundwater, which can result in increased water storage and changes in the regional water balance.

\section{Conflict of Interests}

The authors declare that there is no conflict of interests regarding the publication of this paper.

\section{Acknowledgments}

This study was supported by the National Key Program for Developing Basic Sciences in China (no. 2013CBA01806), Chinese Academy of Sciences (KJZD-EW-G03-04), National Natural Science Foundation of China (41121001, 41225002, and 41471060), and the Foundation for Young Talents in Cold and Arid Regions Environmental and Engineering Research Institute of CAS (no. Y451191001). The authors would like to thank the editors and the anonymous reviewers for their crucial comments, which improved the quality of this paper.

\section{References}

[1] B. Ye, Y. Ding, K. Jiao, and J. Zhang, "Cold runoff response to climate change," Quaternary Sciences, vol. 32, pp. 103-110, 2012.

[2] C. Xi, Physical Geography of Arid Land in China, Science Press, Beijing, China, 2010.

[3] G. Zhu, Investigations on Time-Variation of Continental Water Storage with GRACE Gravity Models, Chinese Academy of Surveying and Mapping, Beijing, China, 2007.

[4] M. Zhong, J. Duan, H. Xu, P. Peng, H. Yan, and Y. Zhu, "Trend of China land water storage redistribution at mediand large-spatial scales in recent five years by satellite gravity observations," Chinese Science Bulletin, vol. 54, no. 5, pp. 816821, 2009.

[5] M. Xu, B. Ye, Q. Zhao, S. Zhang, and J. Wang, "Estimation of water balance in the source region of the Yellow River based on GRACE satellite data," Journal of Arid Land, vol. 5, no. 3, pp. 384-395, 2013.

[6] Y. Ding and R. Shou, Northwest China Region Climate and Ecological Environment, China Meteorological Press, Beijing, China, 2001.

[7] J. Wahr, M. Molenaar, and F. Bryan, "Time variability of the Earth's gravity field: hydrological and oceanic effects and their possible detection using GRACE," Journal of Geophysical Research B: Solid Earth, vol. 103, no. 12, pp. 30205-30229, 1998.

[8] B. D. Tapley, S. Bettadpur, J. C. Ries, P. F. Thompson, and M. M. Watkins, "GRACE measurements of mass variability in the Earth system," Science, vol. 305, no. 5683, pp. 503-505, 2004.

[9] S. B. Luthcke, H. J. Zwally, W. Abdalati et al., "Recent greenland ice mass loss by drainage system from satellite gravity observations," Science, vol. 314, no. 5803, pp. 1286-1289, 2006. 
[10] S. Bettadpur, GRACE level-2 Gravity Field Product User Handbook, Center for Space Research, The University of Texas at Austin, Austin, Tex, USA, 2003.

[11] O. B. Andersen and J. Hinderer, "Global inter-annual gravity changes from GRACE: early results," Geophysical Research Letters, vol. 32, no. 1, pp. 1-4, 2005.

[12] G. Ramillien, A. Cazenave, and O. Brunau, "Global time variations of hydrological signals from GRACE satellite gravimetry," Geophysical Journal International, vol. 158, no. 3, pp. 813-826, 2004.

[13] A. Güntner, "Improvement of global hydrological models using GRACE data," Surveys in Geophysics, vol. 29, no. 4-5, pp. 375397, 2008.

[14] D. D. Rowlands, S. B. Luthcke, S. M. Klosko et al., "Resolving mass flux at high spatial and temporal resolution using GRACE intersatellite measurements," Geophysical Research Letters, vol. 32, no. 4, article L4310, 2005.

[15] D. Jianbin, Z. Min, Y. Haoming, and J. Min, "Recovery of land water storage varitions in Chinese Mainland by use of GRACE data," Journal of Geodesy and Geodynamics, vol. 27, no. 3, pp. 68-71, 2007.

[16] X. Su, J. Ping, and Q. Ye, "Study on water storage change useing GRACE data in North China," Chinese Science (Earth Science), vol. 42, pp. 917-922, 2012.

[17] G. Strassberg, B. R. Scanlon, and D. Chambers, "Evaluation of groundwater storage monitoring with the GRACE satellite: case study of the high plains aquifer, Central United States," Water Resources Research, vol. 45, no. 5, Article ID W054102009, 2009.

[18] R. R. Muskett and V. E. Romanovsky, "Alaskan permafrost groundwater storage changes derived from GRACE and ground measurements," Remote Sensing, vol. 3, no. 2, pp. 378-397, 2011.

[19] S.-H. Ye, X.-L. Su, J.-S. Ping, and Q. Huang, "Land water storage variations in China and adjacent areas revealed by the GRACE gravity mission," Journal of Jilin University, vol. 41, no. 5, pp. 1580-1586, 2011.

[20] X. G. Hu, J. Chen, Y. Zhou, C. Huang, and X. H. Miao, "GRACE space gravity measurements to monitor the use of the Yangtze River seasonal changes in water storage," Science in China: Earth Science, vol. 36, pp. 225-232, 2006.

[21] H.-S. Wang, Z.-Y. Wang, X.-D. Yuan, P. Wu, and E. Rangelova, "Water storage changes in Three Gorges water systems area inferred from GRACE time-variable gravity data," Chinese Journal of Geophysics, vol. 50, no. 3, pp. 730-736, 2007.

[22] L. Xing, H. Li, D. Liu, and X. Zhou, "Monthly water distribution in Chinaand its adjacent area from time-variation gravity of GRACE," Journal of Geodesy and Geodynamics, vol. 27, pp. 3538, 2007.

[23] Y. Yang, E. Dongchen, D. Chao, and H. Wang, "Seasonal and inter-annual change in land water storage from GRACE," Chinese Journal of Geophysics, vol. 52, pp. 298-299, 2009.

[24] Y. Cao and Z. Nan, "Monitoring water storage variations in the heihe river basin by the GRACE gravity satellite," Remote Sensing Technology and Application, vol. 26, no. 6, pp. 719-727, 2011.

[25] P. Xu and W. Zhang, "Inversion of terrestrial water storage changes in recent years for Qinghai-Tibetan plateau and Yarlung Zangbo River basin by GRACE," Journal of Water Resources \& Water Engineering, vol. 24, pp. 23-29, 2013.

[26] R. Jiawen, Y. Baisheng, D. Yongjian, and L. Shiyin, "Preliminary estimates the potential contribution of cryospheric changes to sea level rise in China," Chinese Science Bulletin, vol. 56, pp. 1084-1087, 2013.
[27] Z. Li, K. Li, and L. Wang, "Recent glacier change and its impact on water resources in Xinjiang," Quaternary Sciences, vol. 30, pp. 96-106, 2010.

[28] Y. Ding, D. Yang, B. Ye, and N. Wang, "Effects of bias correction on precipitation trend over China," Journal of Geophysical Research D: Atmospheres, vol. 112, no. 13, Article ID D13116, 2007.

[29] M. Xu, Y. Wang, Z. Y. Zhou, S. H. Yi, and B. S. Ye, "Discussion of methods on spatial interpolation for monthly temperature data in Yangtze River basin," Resources and Environment in the Yangtze Basin, vol. 21, pp. 327-334, 2012.

[30] I. Velicogna and J. Wahr, "Measurements of time-variable gravity show mass loss in Antarctica," Science, vol. 311, no. 5768, pp. 1754-1756, 2006.

[31] G. Strassberg, B. R. Scanlon, and M. Rodell, "Comparison of seasonal terrestrial water storage variations from GRACE with groundwater-level measurements from the High Plains Aquifer (USA)," Geophysical Research Letters, vol. 34, no. 14, Article ID L14402, 2007.

[32] Z. Qidong, X. Cunde, and Q. Dahe, "In recent decades the Himalayan glacier change and its impact on water resources," Journal of Glaciology and Geocryology, vol. 31, pp. 885-895, 2009.

[33] H. Lv, Nearly 40 Years in Response to Fluctuations in the Himalayan Glaciers to Climate Change, Lanzhou University, Lanzhou, China, 2013.

[34] S. B. Kapnick, T. L. Delworth, M. Ashfaq, S. Malyshev, and P. C. Milly, "Snowfall less sensitive to warming in Karakoram than in Himalayas due to a unique seasonal cycle," Nature Geoscience, vol. 7, no. 11, pp. 834-840, 2014.

[35] S. Yongping, S. Hongchao, and W. Guoya, "The responses of glaciers and snow cover to climate change in Xinjiang(1): hydrological effect," Journal of Glaciology and Geocryology, vol. 35, pp. 513-527, 2013.

[36] T. Yao, L. Thompson, W. Yang et al., "Different glacier status with atmospheric circulations in Tibetan Plateau and surroundings," Nature Climate Change, vol. 2, no. 9, pp. 663-667, 2012.

[37] L. Cheng and Y. Qu, Water and Land Resources and Their Rational Development and Utilization in the Hexi Region, Science Press, Beijing, China, 1992.

[38] J. Yang, Z. Jiang, and X. Liu, "Influence research on spring vegetation of Eurasia to summer drought-wetness over the northwest China," Arid Land Geography, vol. 35, pp. 1-9, 2012.

[39] W.-W. Qi, B.-P. Zhang, Y. Pang, F. Zhao, and S. Zhang, “TRMMdata-based spatial and seasonal patterns of precipitation in the Qinghai-Tibet plateau," Scientia Geographica Sinica, vol. 33, no. 8, pp. 999-1005, 2013.

[40] D. Zhang, The Temporal and Spatial Variations of Water Resource over the Tibet Plateau, Lan Zhou University, 2013.

[41] R. R. Muskett and V. E. Romanovsky, "Groundwater storage changes in arctic permafrost watersheds from GRACE and in situ measurements," Environmental Research Letters, vol. 4, no. 4, Article ID 045009, 2009.

[42] T. Bolch, A. Kulkarni, A. Kääb et al., "The state and fate of Himalayan glaciers," Science, vol. 336, no. 6079, pp. 310-314, 2012.

[43] K. Hewitt, "The Karakoram anomaly? Glacier expantion and the 'elevation effect,' Karakoram Himalaya," Mountain Research and Development, vol. 25, no. 4, pp. 332-340, 2005.

[44] J. Gardelle, E. Berthier, and Y. Arnaud, "Slight mass gain of Karakoram glaciers in the early twenty-first century," Nature Geoscience, vol. 5, no. 5, pp. 322-325, 2012. 
[45] M. Xu, B. Ye, and Q. Zhao, “Temporal and spatial patterns of water storage change of Tianshan in the last 8 years based on GRACE," Arid Zone Research, vol. 30, pp. 404-411, 2013.

[46] M. Xu, S. Zhang, J. Wang, Q. Zhao, and C. Zhao, “Temporal and spatial patterns of water storage change of Qilian Mountains in recent 8 years based on GRACE," Arid Land Geography, vol. 37, pp. 458-467, 2014. 

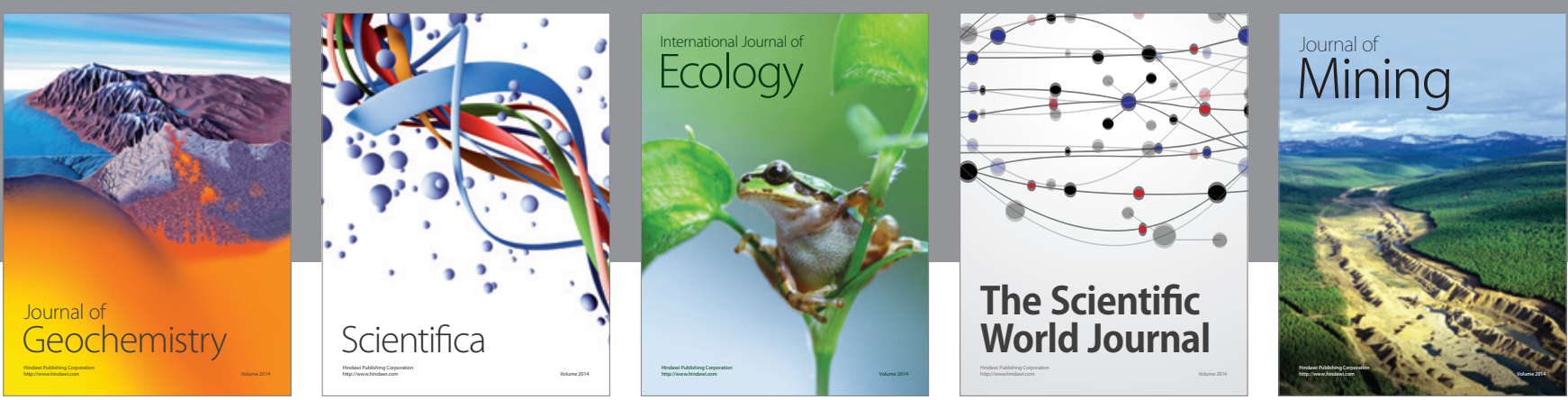

The Scientific World Journal
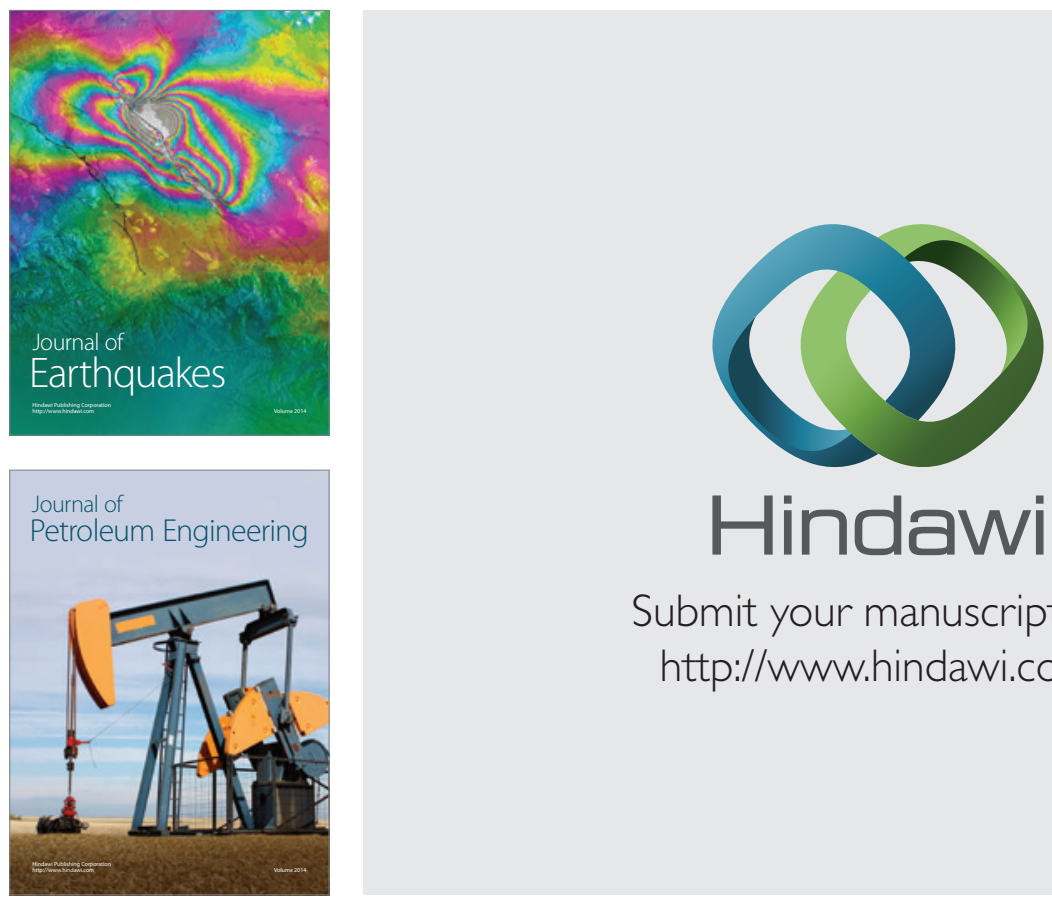

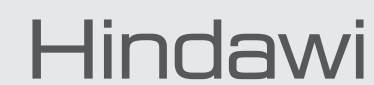

Submit your manuscripts at

http://www.hindawi.com
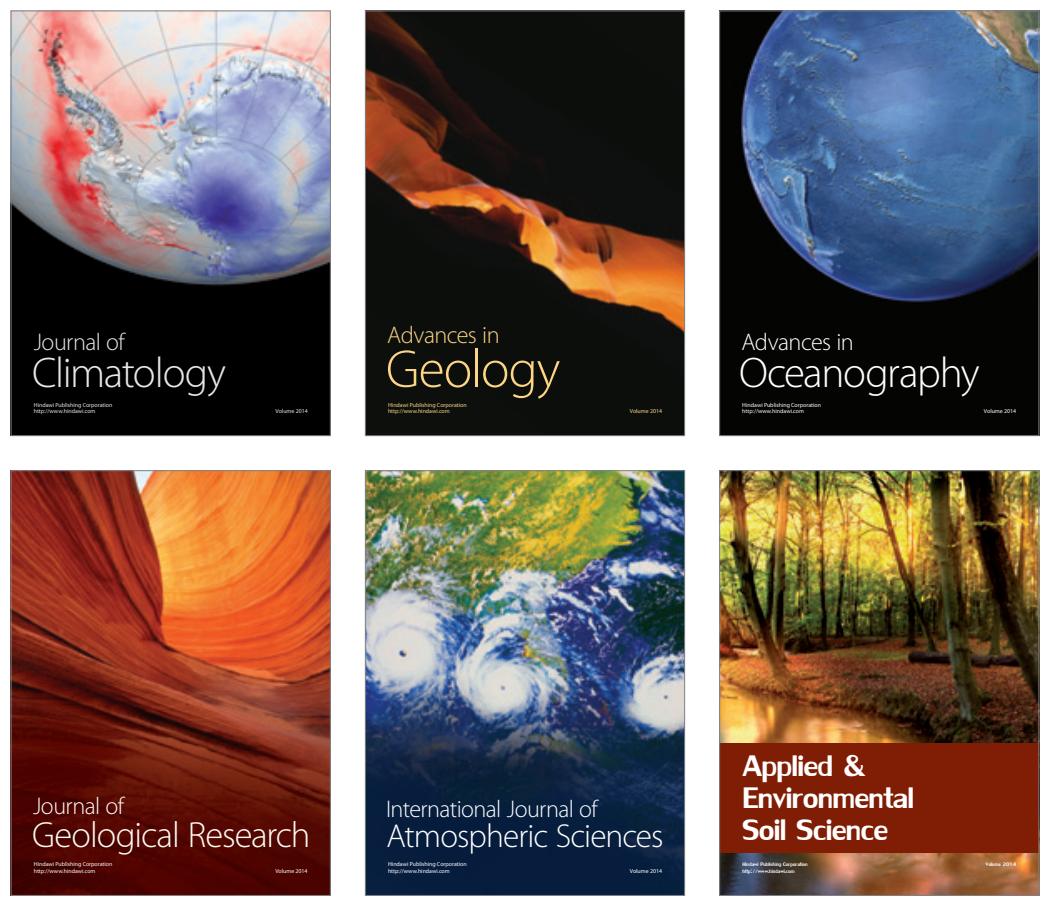
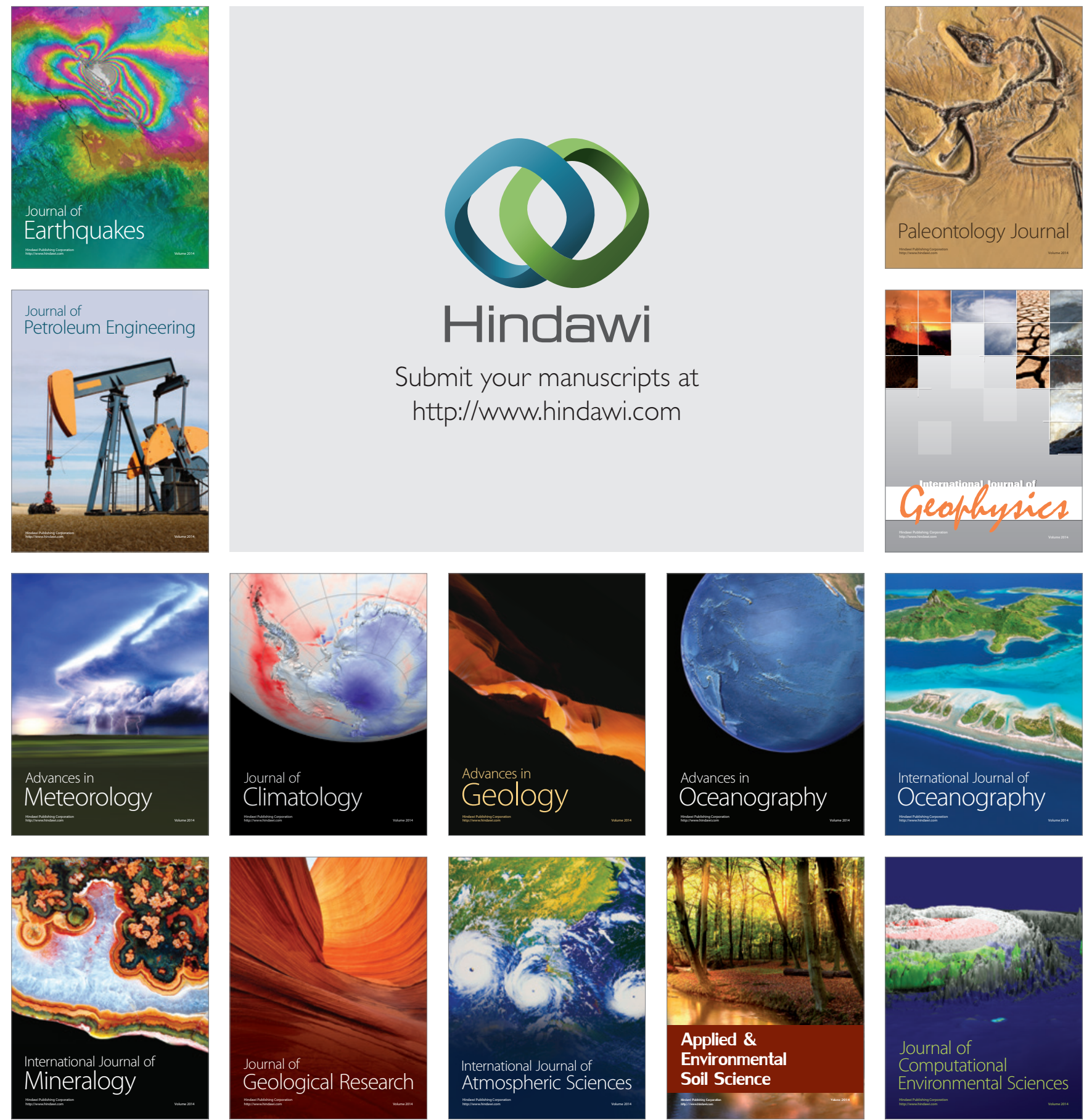